\title{
ASPECTOS JURÍDICOS DO TRANSPLANTE DE ÚTERO: UM ESTUDO SOB PERSPECTIVA DA SOCIEDADE DA INFORMAÇÃO
}

\author{
Denise Souza Amorim ${ }^{1}$ \\ Irineu Francisco Barreto Junior ${ }^{2}$
}

\section{Resumo:}

Este artigo analisa o transplante de útero, técnica experimental de implantação de um órgão de doadora viva ou cadáver em pacientes pré-determinados, enquanto direito à saúde reprodutiva. Destaca que a amplitude do tema saúde e seu destaque na agenda internacional são diretamente relacionados ao histórico social e político dos povos. Conclui que o conceito de saúde não pode ser entendido sem o abrigo dos direitos de liberdade, igualdade e solidariedade entre os povos e as gerações. Ciência e medicina avançam abruptamente, limites estabelecidos por preceitos éticos são necessários e o poder público não pode ser omisso diante dessas mutações.

Palavras-chave: Sociedade da Informação, Saúde Reprodutiva, Direito à Saúde, Políticas Públicas, Direitos Fundamentais.

\section{LEGAL ASPECTS OF UTERINE TRANSPLANTATION: A STUDY FROM THE PERSPECTIVE OF THE INFORMATION SOCIETY}

\begin{abstract}
:
This paper analyzes uterine transplantation as the experimental technique for implanting a living donor organ or cadaver in patients like a reproductive right. He points out that the breadth of the health theme and its prominence in the international agenda are directly related to the social and political history. It concludes that the concept of health cannot be understood without the shelter of the rights of liberty, equality and solidarity. Science and medicine advance abruptly, boundaries set by ethical precepts are necessary and the public power cannot be silent in the face of these mutations.
\end{abstract}

Keywords: Information society, Reproductive health, Right to health, Public policy, Fundamental rights.

\section{Introdução}

Este artigo analisa o transplante de útero (ou transplante uterino), técnica experimental de implantação de um órgão de doadora viva ou cadáver em pacientes com útero

\footnotetext{
${ }^{1}$ Mestranda pelo Programa de Mestrado em Direito da Sociedade da Informação - FMU-SP. Especialista em Direito do Trabalho pela PUC-RS e em fisioterapia pmeumofuncional pela Santa Casa de SP. Advogada.

${ }^{2}$ Pós Doutor em Sociologia pela Faculdade de Filosofia, Letras e Ciências Humanas (FFLCH) da Universidade de São Paulo - USP. Doutor em Ciências Sociais pela Pontifícia Universidade Católica de São Paulo - PUC-SP. Docente do Programa de Mestrado em Direito da Sociedade da Informação e do Curso de Graduação em Direito da FMU-SP. Coordenador do Grupo de Pesquisa Direito, Tecnologia e Sociedade. Analista de Pesquisas da Fundação Sistema Estadual de Análise de Dados Seade.
} 
que não pode ser recuperado cirurgicamente ou pacientes com ausência do órgão (retirados cirurgicamente ou ausência congênita), como alternativa ao tratamento da infertilidade de causa uterina e inserido no amplo rol de direitos reprodutivos conforme preconiza a Constituição Federal de 1988, ao estabelecer o direito à saúde como fundamental.

A importância do tema saúde na agenda mundial adveio de uma aceitação da existência de direitos que pertencem a toda humanidade. Exemplo disso é a Declaração de Istambul, documento publicado em maio de 2009, que marcou o final do Congresso da Federação Mundial de Saúde Pública, realizado na Turquia, e reuniu 70 associações nacionais de saúde pública, entre as quais a Associação Brasileira de Pós-Graduação em Saúde Coletiva (ABRASCO), e regionais como a da Europa, European Public Health Association (EUPHA), e da América Latina, Asociación Latinamericana y del Caribe de Educación em Salud Pública (ALAESP). A frase que abre a Declaração de Istambul (Turquia) não deixa margens para questionamentos: "A proteção da saúde da população é a primeira responsabilidade dos governos em todos os níveis, entre os quais, em especial, os chefes de Estado e primeirosministros" (SINDHOSP, 2010, p.59).

A amplitude do tema saúde como direito, tal como o seu destaque na agenda internacional, estão diretamente relacionados ao histórico social e político dos povos. Assim, o conceito de saúde não pode ser entendido sem o recurso aos direitos de liberdade, de igualdade e de solidariedade entre os povos e as gerações.

Para ilustrar a importância da temática saúde na agenda internacional, desde a fundação em 1948 da Organização Mundial da Saúde (OMS), até os dias atuais, a entidade conquistou grandes vitórias para a saúde pública mundial, um dos mais importantes eventos foi a reunião, em 2000, de 191 nações na Cúpula do Milênio, realizada em Nova York (Estados Unidos), na qual as nações envolvidas oficializaram um pacto que estabelece oito metas para tornar o mundo mais justo até 2015, sendo que três dos oito objetivos se relacionam diretamente com a saúde.

O acordo resultou nos Objetivos de Desenvolvimento do Milênio. As metas são: erradicar a extrema pobreza e a fome; atingir o ensino básico universal; promover a igualdade entre os sexos e a autonomia da mulher; reduzir a mortalidade infantil; melhorar a saúde 
materna; combater o HIV/AIDS, malária e outras doenças; garantir a sustentabilidade ambiental; e estabelecer uma parceria mundial para o desenvolvimento. 3

\section{Do direito à Saúde}

O Poder Constituinte de 1988 reconheceu, sob a denominação de direitos sociais, um conjunto híbrido e abrangente de direitos designados de fundamentais pelo título II da Constituição Federal, sendo o direito à saúde parte que integra o rol desses direitos sociais. A saúde é estabelecida como um direito universal que deve ser garantido pelo Estado. Assim, o Sistema Único de Saúde (SUS), institucionalizado pela Lei Federal no 8.080 em 1990 - Lei Orgânica da Saúde (LOS), possui como princípios a universalidade de acesso aos serviços de saúde e a integralidade da assistência, cabendo a ele a execução de ações de assistência terapêutica integral, inclusive farmacêutica (art. $6^{\circ}$ ). Ambas, a Constituição Federal e a Lei Federal nº 8.080/90 - Lei Orgânica da Saúde (LOS) - definem o objeto do direito à saúde incorporando o conceito da Organização Mundial da Saúde: "um estado de completo bemestar físico, mental e social e não apenas a simples ausência de doenças e outros danos. "

Assim, a Constituição da República Federativa do Brasil de 1988 inseriu o direito à saúde como um direito social, (art. $6^{\circ}$ ), entre os direitos e garantias fundamentais. Da mesma forma, instituiu o artigo 194 inserindo a saúde no sistema de seguridade social do país, ao lado dos artigos 196 a 201 da CF que, por sua vez, fixaram uma estrutura política complexa e abrangente para o sistema de saúde brasileiro.

Em consonância com o preceito constitucional, a Lei no 8.080 em 1990 - Lei Orgânica da Saúde (LOAS) - deu ressonância a vários princípios constitucionais, estabeleceu no artigo $2^{\circ}$ que a saúde é um direito fundamental e ainda no artigo $7^{\circ}$, II, que prenunciou assistência integral como conjunto articulado de ações e serviços públicos que propiciem aos indivíduos e à coletividade atenção eficiente e adequada em todos os níveis de complexidade do sistema. A constitucionalização do direito à saúde acarretou um aumento formal e material de sua força normativa com inúmeras consequências práticas, sobretudo, quanto à sua

\footnotetext{
${ }^{3}$ Programa das Nações Unidas para o Desenvolvimento. Disponível em http://www.pnud.org.br. Acessado em 19.08.2011.
} 
efetividade, considerada como a materialização da norma no mundo dos fatos, a realização do direito, o desempenho concreto de sua função social.

A metodologia do artigo filia-se à linha jurídico-dogmática que considera o direito com autossuficiência metodológica e trabalha com os elementos internos ao ordenamento jurídico. Essa abordagem desenvolve investigações com vistas à compreensão das relações normativas nos vários campos do direito e com a avaliação das estruturas interiores ao ordenamento jurídico (GUSTIN; DIAS, 2006, p.20-25)). Aborda ainda a linha investigativa Jurídico Sociológica que se propõe a compreender o fenômeno jurídico no ambiente social mais amplo. Para tal, analisa o direito como variável dependente da sociedade e trabalha com as noções de eficiência, eficácia e efetividade das relações entre direito e sociedade. Preocupa-se com a facticidade do Direito e com as relações contraditórias que estabelece com o próprio Direito e com os demais campos: sociocultural, político e antropológico (GUSTIN; DIAS, 2006, p.20-25).

\section{Direito Reprodutivo na Sociedade da Informação}

A Organização Mundial da Saúde (OMS) em 1947 conceituou a saúde como completo bem-estar físico, mental e social e não apenas ausência de doença e outros agravos. Fuller (2011, p.89) destaca que o "bem-estar" acaba por fixar um conceito subjetivo e fruto de experiência pessoal de satisfação emocional da vida de cada um. Contudo o conceito proposto pela OMS enfatiza que a saúde não é de responsabilidade exclusiva do setor da saúde, mas transdisciplinar. Isso é corroborado pelo caráter integrado dos Objetivos de Desenvolvimento Sustentável (ODS) e suas metas, que pode facilitar a integração de políticas nos diversos setores (OPAS, 2017, p.2). Waldman (2018, p.151) reconhece o direito à saúde como uma prioridade das Nações Unidas no ODS n³ que almeja "assegurar uma vida saudável e promover o bem-estar para todos e todas, em todas as idades".

No Brasil, o direito à saúde está positivado como direito fundamental na Constituição Federa a partir de 1988, destacando o acesso à saúde pública, como direito social de todos (SIPPERT; STURZA, 2018, p.68). Irrefutável a afirmação de Fuller e Lisboa (2018, p.18) de que a "saúde é um direito humano por excelência e, como tal, reflete a ideia de ser uma exigência da dignidade da vida, da liberdade e da igualdade humana, devendo ser reconhecida positivamente pelos ordenamentos jurídicos”. Barreto Junior e Pavani (2013, p.85) observam 
que a saúde integra a ordem dos direitos fundamentais e está implícito em seu comando a ordem de pertencer ao ser humano como gênero, não podendo, portanto, ficar limitada a um grupo, categoria ou classes de pessoas. Contudo a saúde tem um aspecto econômico forte, haja vista ser um segmento de mercado que movimenta milhões anualmente conforme destacado por Zalazar e Carranza (2018, p.29):

El mercado de la salud mueve millones y millones de dólares por año, no solo a través de la pretación del serviço sanitário, sino también por las farmacêuticas cuyo objetivo es el descubrimiento y la creación de remédios para las enfermidades. La salud es um objeto del mercado y es parte de él, ya distintos sectores de producción forman un engranaje que da cuenta da le necesidad de la atnción de la salud como um subsistema de la economia global.

Sanches e Cavalcanti (2018, p.464) apontam a saúde como um direito fundamental, é o direito que nos permite viver com dignidade e possibilita uma sadia qualidade de vida e bem-estar. A partir dessa breve analise da concepção de saúde podemos concluir que a reprodução humana compõe o exercício de uma vida saudável, de forma que o direito reprodutivo passou a integrar o rol dos direitos fundamentais. Ventura (2009, p.19) define o direito reprodutivo como "um conjunto de direitos individuais e sociais que devem interagir em busca do pleno exercício da sexualidade e reprodução humana". Essa concepção engloba uma perspectiva de igualdade e equidade nas relações pessoais e sociais e uma ampliação das obrigações do Estado na promoção, efetivação e implementação desses direitos. Em 1994 na Conferência Internacional sobre População e Desenvolvimento, no Cairo, esse conceito foi legitimado e a partir daí estabeleceram novos modelos de intervenção na saúde reprodutiva de ação jurídica, comprometidos com os princípios dos direitos humanos:

O público-alvo do Plano de Ação do Cairo constitui-se de casais, adolescentes, mulheres solteiras, homens e pessoas idosas, que deverão ser alcançados pelos programas e políticas públicas e pelas normas legais que garantem os direitos reprodutivos. Nesse sentido, a Conferência do Cairo representa um avanço na conquista de direitos por parte desses segmentos da população. Até então, as pessoas que estivessem fora da estrutura de casal eram negligenciadas pelas políticas públicas relacionadas à sexualidade e à reprodução, resultando na restrição aos meios para exercer amplamente esses direitos. (VENTURA, 2009, p.21)

A sociedade contemporânea, a qual convencionou-se denominar como Sociedade de Informação, convive com avanços tecnológicos promotores de benefícios que vão além de conforto e amplo acesso a comunicação, no âmbito de saúde, por exemplo, as técnicas evoluíram propiciando aumento na longevidade com qualidade de vida. Lisboa (2006, p.85) define como Sociedade da Informação o período histórico a partir da preponderância da 
informação sobre os meios de produção e distribuição dos bens da sociedade. Casttells (2018, p.66) pondera que apesar dessa sociedade estar integrada por uma rede, as desigualdades e exclusões tornam-se latentes. Nesse tocante Leite, Simão Filho e Vigliar (2016, p.154) asseveram a necessidade de proporcionar uma comunicação integrada e da forma mais ampla possível viabilizando a transferência do saber, como tarefa imprescindível para o alcançar o objetivo base dessa sociedade.

A revolução tecnológica ocorrida nos meios de comunicação, desde meados da década de 1990, deu origem a uma nova era denominada como Sociedade da Informação. A sua principal característica é a geração e propagação de informações, advindas de qualquer lugar do mundo, em tempo quase que real e de forma inédita na história da tecnologia (BARRETO JUNIOR, p. 100-127.). Denota-se que a informação é o centro gravitacional desta nova era ou, em outras palavras, é possível afirmar que ela possui valor comercial.

O conceito de Sociedade da Informação tal como foi preconizado no Livro Verde, em setembro de 2000, pelo Ministério da Ciência e Tecnologia, atual Ministério da Ciência, Tecnologia, Inovações e Comunicações, foi componente determinante do plano governamental que inaugurou essa nova era em decorrência da necessidade de impulsionar e adaptar o país em decorrência do avanço das tecnologias da informação. Barreto Junior (2007, p.62) recorre a Castells para salientar a necessidade de "expandir as transformações verificadas no cenário mundial com o advento dos avanços tecnológicos para além das fronteiras técnicas, apontando para as transformações na economia, nas relações sociais, na cultura, ou, em síntese, nas mais diversas relações que envolvam a humanidade”.

Nas últimas duas décadas cresceu de forma exponencial a captação desses dados e, no Brasil, inexistem mecanismos efetivos para proteção dos parâmetros mínimos de privacidade dos usuários de tecnologias e aplicações de internet - não obstante a existência do Marco Civil da Internet (Lei 12.965/2014) e suas determinações normativas quanto à necessidade do livre esclarecimento e consentimento como requisito para a coleta, uso, armazenamento, tratamento e proteção de dados pessoais, não é isso que se observa em termos práticos (LIMA; BARRETO JUNIOR, p. 241). 
Fuller e Lisboa (2018, p. 22) destacam a tríade saúde, Sociedade da Informação e solidarismo para obtenção de desenvolvimento social, econômico e cultural, assegurando ao individuo o valor-fonte do sistema jurídico, destacando a distinção entre solidarismo e individualismo: "o solidarismo não busca somente a harmonização dos interesses e o suprimento das necessidades pessoais, buscando-se, destarte, a erradicação da pobreza e o desenvolvimento pessoal".

\section{Transplante de Útero - Aspectos técnicos}

O transplante de útero (ou transplante uterino) consiste na técnica experimental de implantação de um órgão de doadora viva ou cadáver em pacientes com útero que não pode ser recuperado cirurgicamente ou pacientes com ausência do órgão (retirados cirurgicamente ou ausência congênita) como alternativa ao tratamento da infertilidade de causa uterina (FEBRASGO, 2017). Atualmente esse tipo de infertilidade possui apenas a gravidez em útero de substituição como possibilidade terapêutica ${ }^{4}$.

Inegável que gerar uma vida em outro útero desencadeie conflitos éticos, morais, religiosos e jurídicos como questões que envolvem a possibilidade da compensação da mulher que irá gerar, o vínculo afetivo com a criança e em relação a filiação (a mulher que concorde em participar deste processo estará vinculada a abrir mão da maternidade propriamente dita) (CARDIN, 2016, p.30). A técnica está regulamentada administrativamente através de resoluções do Conselho Federal de Medicina e isso amplia os estigmas sociais sendo uma opção terapêutica de pequena adesão. A resolução 2.168/17 do Conselho Federal de Medicina dispõe:

VII - SOBRE A GESTAÇÃO DE SUBSTITUIÇÃO (CESSÃO TEMPORÁRIA DO ÚTERO). As clínicas, centros ou serviços de reprodução assistida podem usar técnicas de RA para criarem a situação identificada como gestação de substituição, desde que exista um problema médico que impeça ou contraindique a gestação na doadora genética, em união homoafetiva ou pessoa solteira.

1. A cedente temporária do útero deve pertencer à família de um dos parceiros em parentesco consanguíneo até o quarto grau (primeiro grau - mãe/filha; segundo grau

\footnotetext{
${ }^{4}$ Infertilidade por fator uterino corresponde a situação em que o útero possui alteração que limite a gestação e não possa ser tratado cirurgicamente, ou em pacientes com ausência do órgão (retirado cirurgicamente, ou anomalias genéticas que não propiciaram seu desenvolvimento normal. (FEBRASGO, 2017)
} 
- avó/irmã; terceiro grau - tia/sobrinha; quarto grau - prima). Demais casos estão sujeitos à autorização do Conselho Regional de Medicina. ${ }^{5}$

O transplante de útero surge com o objetivo de proporcionar a capacidade de gerar, e o exercício maternidade em sua plenitude a mulheres que tiveram essa capacidade tolhida seja por questões biológicas ou adquiridas.

\subsection{Aspectos Históricos}

A Arábia Saudita, em 2000, realizou o primeiro transplante de útero intervivos, porém o órgão precisou ser retirado após três meses devido necrose (morte celular). Em 2011, a Turquia realiza o segundo transplante, com doadora falecida, foram concebidas duas gestações sem sucesso, em ambas ocorreu o abortamento precoce. Novos estudos ocorrem na Suécia em 2013, com a realizado de nove transplantes com doadoras vivas. A primeira gestação com nascido vivo do mundo ocorreu nesse grupo, apenas em 2014.

No Brasil o primeiro caso de transplante de útero ocorreu em 2016 e foi amplamente noticiado dado o fato de ser o único no mundo em caso de nascido vivo com doadora falecida, morte cerebral (GLOBO, 2017). A Revista Crescer, no dia 10 de Abril de 2019, veiculou o nascimento do primeiro bebê, na Suécia, de um útero transplantado por procedimento robótico o que torna a técnica menos invasiva para a receptora, minimizando os riscos do procedimento. Dibyangshu Sarkar noticiou na RIF, no dia 12 de abril de 2019, o primeiro transplante de útero na França, em que a doadora foi a mãe da transplantada (portadora da síndrome de Rokitansky, nasceu sem útero). A matéria traz a luz o debate ético que ocorreu após a divulgação do estudo:

O jornal católico La Croix levanta a questão ética sobre o procedimento, citando a Academia de Medicina da França, que já em 2015 falava sobre a especificidade dessa operação. A entidade lembra que esse tipo de transplante "não é vital, pois o objetivo não é de assegurar a sobrevivência de uma pessoa" ou de melhorar a qualidade de vida de um paciente, como no caso de um transplante de mão ou rosto. A cirurgia "proporciona à mulher o sentimento de reparação de uma injustiça da natureza", diz a Academia, que se questiona em seguida: "Deve-se colocar em risco a vida de uma mãe por causa de um órgão ausente?". A entidade também questiona as reações possíveis de uma criança ao tomar consciência de ter vindo ao mundo a partir do útero da avó ou de uma desconhecida, explica o jornal La Croix. (SARKAR, 2019)

\footnotetext{
${ }^{5}$ Redação atualizada, na resolução anterior o termo "doação temporária de útero" foi substituído por cessão temporária de útero haja vista que nessa modalidade de tratamento não há a transferência do órgão de uma pessoa para outra.
} 
Os estudos avançam em países que possuem cultural mais liberal em relação as questões cientificas, mas sempre envoltos de questionamentos éticos e morais.

\subsection{A transitoriedade do transplante de útero}

Apesar dos experimentos com transplante uterino serem relativamente novos na medicina, os resultados evoluem satisfatoriamente. Até o momento 16 bebês nasceram de úteros transplantados. A técnica de transplante de útero diferentemente do transplante de outros órgãos possui características peculiares da quais destacamos: o útero não é um órgão vital, e após a gestação recomenda-se a retirada do órgão transplantado.

O processo de doação-transplante vem se sedimentando na sociedade ao longo dos anos. A informação e o conhecimento dos benefícios minimizaram o temor social que pairava nas últimas décadas. Garcia et al. (2015, p.61) apontam que o desenvolvimento dos transplantes e sua aplicação no tratamento das doenças terminais de alguns órgãos converteram-se num dos capítulos de maior êxito na história da medicina, com resultados progressivamente melhores. Entretanto imperava a luta pela vida e os transplantes eram exclusivamente de órgãos vitais, sem os quais é impossível viver.

Os avanços tecnológicos melhoram a performance cirúrgicas, minimizando as complicações e diminuindo a mortalidade. Logo os experimentos progrediram em duas vertentes: estudos do código genético (alteração da cadeia de DNA e pesquisas com células troncos) e técnicas cirúrgicas que permitiram não só a vida, mas objetivavam a qualidade de vida. Atualmente encontramos na literatura relatos de transplante de face, pele, membros (principalmente mão) que objetivam restaurar a funcionalidade, melhorando a qualidade de vida. Diferentemente do transplante de útero que não almeja restaurar, mas possibilitar (sem garantias) a gestação.

O transplante uterino possui uma característica única dentre os transplantes conforme apontamento da FEBRASGO (2017): o órgão é mantido até a paciente conseguir gerar o número de filhos desejados e então ele é removido por histerectomia ou por descontinuação da imunossupressão. Essa característica suscita conflitos na órbita da ética, moral e traz a luz discussões de princípios fundamentais do Biodireito: vida, dignidade da pessoa humana, primum non nocere. Após a realização do transplante é necessário que a receptora fique imunossuprimida afim de evitar rejeição do órgão transplantado. Decorrida a primeira fase, 
será realizado a processo de fertilização e obtendo sucesso, a tão esperada gravidez, e posteriormente a histerectomia ${ }^{6}$ para diminuir os riscos da exposição aos imunossupressores. Importante salientar que em caso de transplante de doadora viva, esta será submetida ao procedimento cirúrgico de retirada do útero e ficará impossibilitada de gerar novos filhos. Nesse caso os riscos extrapolam a figura do receptor, colocando em risco vida de terceiro.

\section{Conflitos bioéticos e aspectos jurídicos do Transplante de Útero}

O Brasil, têm em seu bojo, uma cultura patriarcal e religiosa dominante no âmbito do direito reprodutivo, Matos e Araújo (2018, p. 138) indicam que predomina a ideia de família monogâmica, legitimada pelo casamento, onde: "a reprodução socialmente aceita e desejada é aquela que se convencionou chamar de boa maternidade/paternidade". Contudo esse modelo de reprodução "desejado" sofre impactos das diversas e variadas formas de se relacionar na Sociedade da Informação, Bauman (2004, p.13) afirma que "as relações virtuais (rebatizadas de 'conexões') estabelecem o padrão que orienta todos os outros relacionamentos", relações liquidas. O transplante de útero poderá permitir a possibilidade de gerar um filho por mulheres com condições limitantes, independente do seu estado civil.

Imprescindível destacar a diferença entre gravidez e maternidade. A primeira corresponde ao período de cerca de quarenta semanas entre o momento da concepção e o parto; é uma fase limitada temporalmente, enquanto que a maternidade não corresponde a um acontecimento biológico, mas a uma vivência inscrita em uma dinâmica sócio-histórica e envolve a prestação de cuidados e o envolvimento afetivo (CORREIA, 1998, p.366). Desta forma a impossibilidade de gerar um filho não representa o exercício da maternidade, há mulheres que encontram a satisfação alternativas como por exemplo a adoção. A necessidade de gerar um filho está relacionada a fatores intrínsecos e subjetivos. Essa condição não expõe a vida a risco, mas limita o bem-estar em sua plenitude, afetando por vezes a saúde emocional, implicando no gozo da dignidade da pessoa humana.

Contudo conceituar o princípio da Dignidade da Pessoa Humana é sem dúvida um dos grandes dilemas da sociedade contemporânea, pois comtempla diversos valores em seu arcabouço. Nesse sentido Ferrajoli (2011, p.104-105) estabelece que a dignidade deve ser

\footnotetext{
${ }^{6}$ Procedimento de retirada cirúrgica do útero transplantado, que será realizado mediante consentimento da receptora.
} 
analisada sobre o prisma de ser considerada de ser considerada um principio e o próprio fundamento da República Federativa do Brasil. Em sociedades marcadas no Cristianismo, a proteção à pessoa humana sofre influências da ideia do homem criado à imagem e semelhança de Deus:

\begin{abstract}
Em primeiro lugar, a proteção à Pessoa Humana, como derivação lógica da dignidade das Pessoas Divinas, consubstanciadas em; um só Deus. Conforme Vaz: [foi] sem dúvida a revelação da pessoa nos mistérios cristológico e trinitário que apontou para o núcleo essencial a partir do qual foi possível pensar a analogia entre as pessoas divinas e a pessoa humana" $\mathrm{O}$ epicentro da questão está, no entanto, no momento em que se percebe serem a Pessoa Humana (como sujeito de direitos) e sua dignidade enquanto "projeto" os centros do ordenamento jurídico - e não meramente a vida como tal. Em segundo lugar, para além dos espaços de pessoalidade, há uma forte tendência em se considerar toda manifestação de vida humana como sagrada. Assim, qualquer traço vital de um ser humano deveria ser respeitado e digno de deferência, haja presença de pessoalidade ou não. (STANCIOLI;CARVALHO;RIBEIRO, LARA, 2011)
\end{abstract}

Comparato (2017) seguindo os preceitos de Kant afirma que a pessoa humana não pode converter-se em instrumento para a realização de um determinado interesse, pois o ser humano, e, de modo geral, todo ser racional, existe como finalidade própria. De forma a concluir que todo homem tem dignidade. Dessa forma em tempos onde a informação é o grande valor da sociedade, e permeia todas as relações e motiva decisões, fica complexo limitar a vida à existência. Viver vai além das funções biológicas primárias, demanda a busca pela felicidade, realização de desejos, alcance de objetivos. Qualquer possibilidade terapêutica que proporcione alcançar bem-estar, ou seja, saúde em sua totalidade será permeada pelos três grandes princípios constitucionais: direito à vida, dignidade da pessoa humana e direito à saúde.

Não obstante, os avanços científicos nas fases das pesquisas frequentemente deparam-se com barreiras éticas e morais e tais conflitos são estudados e disciplinados pela Bioética e pelo Biodireito. Cesar (2018, p.246) assevera que a Bioética introduz limites e princípios reitores a experimentos científicos envolvendo seres humanos, com cunho de coibir a sua coisificação, porém sem coercibilidade intrínseca às normas jurídicas, enquanto que o Biodireito disciplina as repercussões jurídicas advindas de tais experimentos, com normas cogentes e aplicações de sanções.

O estudo da Bioética traz a luz princípios balizadores dentre os quais Koerich, Machado e Costa (2005, p.108) destacam o princípio da beneficência como dever de ajudar aos outros, de fazer ou promover o bem a favor de seus interesses. Reconhece o valor moral 
do outro, levando-se em conta que maximizando o bem do outro, possivelmente pode-se reduzir o mal. Destarte que a busca é pelo máximo de benefícios, reduzindo ao mínimo os danos e riscos, o maior conflito existente diante do transplante de útero, haja vista que os riscos à vida da mulher transplantada são enormes (procedimentos cirúrgicos, imunossupressão, riscos da fertilização e no caso de sucesso de uma gestação delicada) em contraponto de uma possibilidade de gestação. O transplante de útero por si só não assegura a gestação (FEBRASGO, 2017), e vai de encontro ao principio Bioético da não maleficência:

Diego Gracia hierarquizou os princípios dividindo-os em primários ou absolutos (não maleficência e justiça) e secundários ou relativos (beneficência e autonomia). Outorga primazia à não maleficência e à justiça por serem princípios do bem público. Em seu entender, o principio não maleficência está acima da autonomia das pessoas. Os princípios de não maleficência e de justiça, que tendem ao respeito à integridade física e psíquica, além da não discriminação, configuram uma moralidade de mínimos. (PENNA, DUARTE, COHEN, OLIVEIRA, 2012 p. 82)

O respeito à vida física e psíquica, objetivo da não maleficência, é principio fundamental que deve estar acima da autonomia da pessoa (PENNA, DUARTE, COHEN, OLIVEIRA, 2012 p. 85). A Lei N. 9.434 de 1997 aborda o transplante de órgãos e tecidos. Em seu corpo não especifica, nem limitas os órgãos que podem ser transplantados: “Art. $1^{\circ} \mathrm{A}$ disposição gratuita de tecidos, órgãos e partes do corpo humano, em vida ou post mortem, para fins de transplante e tratamento, é permitida na forma desta Lei”. E na Carta Magna especifica no artigo 199, paragrafo 4:

Art. 199. A assistência à saúde é livre à iniciativa privada.

$\S 4^{\circ}$ A lei disporá sobre as condições e os requisitos que facilitem a remoção de órgãos, tecidos e substâncias humanas para fins de transplante, pesquisa e tratamento, bem como a coleta, processamento e transfusão de sangue e seus derivados, sendo vedado todo tipo de comercialização.

Stancioli, et.al (2011) reforça a busca de formas superiores de vida, incessante (re)construção dos projetos pessoais e interpessoais de felicidade, a não interferência de agentes externos (em especial o Estado e a Igreja) nos projetos de vida autônoma e a capacidade de transcender a si mesmo como princípios norteadores para justificar o transplante de órgãos e tecidos. Muito mais que prolongar a vida, a técnica de transplante de órgãos vitais pode propiciar a qualidade de vida, contudo, quando se trata de órgãos não essenciais à vida os riscos devem ser criticamente ponderados. Os princípios do Biodireito balizam esses conflitos norteando as condutas dos limites éticos, conforme asseverou a Ministra Carmem Lucia no seu voto sobre pesquisas com célula tronco: 
Ao fixar a liberdade de pesquisar cientificamente, de informar e de ser informado sobre as pesquisas científicas e seus resultados, sobre usufruir deles quando positivos, segundo padrões éticos que se afinem com os princípios democráticos, a Constituição garante a efetivação do direto à vida digna, propiciando que vivam melhor aqueles que, por qualquer adversidade, não podem contar com a plena condição física, psíquica e mental de saúde. (ROCHA, 2008, p.16)

Os avanços tecnológicos e científicos devem seguir princípios morais e éticos, haja vista que as técnicas alcançadas podem manipular tanto a natureza quanto o homem, sendo a dignidade humana o principal vetor, que seguirá acompanhado do direito a vida e a saúde. De acordo com Paulo Vinicius Sporleder de Souza (2004, p.238) “a humanidade está sendo chamada a administrar responsavelmente o presente e o futuro de sua evolução, nos limites de seu saber e poder".

\section{Conclusão}

A pós-modernidade é um tempo ou momento em que a sociedade está diante de grandes avanços tecnológicos e científicos que podem ser compartilhados com grande velocidade devido ao fluxo quase que instantâneo das informações. É certo que tais avanços despertem nos indivíduos o desejo de situações que pareciam impossíveis de serem alcançadas.

Produzimos vida em laboratório, o sexo biológico do nascimento pode ser modificado, aparelhos podem prolongas a vida, medicamentos controlam avanço das células cancerígenas, transplantes substituem órgãos em falência. Dessa forma parece razoável aventar a possibilidade de gerar um filho a mulheres com condições físicas limitantes. Ocorre que para essas mulheres pode ser um sonho, ou uma meta de vida também poderá resultar em infecções, insuficiências de outros órgãos pelas medicações, morte do feto ou até mesmo morte da gestante.

A realização de um transplante uterino é apenas uma das etapas dentro de um processo de gestação, e que ainda demandaria a associação de técnicas de reprodução assistida, logo, mesmo transplantando a gravidez está longe de ser uma certeza. O desejo da maternidade, não necessariamente demanda a gestação, há mulheres que encontram a realização desse sonho na adoção. 
Ciência e medicina avançam abruptamente, entretanto os limites dados pelos preceitos éticos são necessários. A vida é a essência de tudo desde que fundamentada na dignidade da pessoa humana. O Estado não pode ser omisso diante dessa evolução, regulamento e legislação são necessários para proteger os indivíduos e a sociedade, em um momento em que não há certezas apenas fluidez de informações e verdades. $\mathrm{O}$ assunto é extenso, denso e polêmico e não se esgota aqui, sugerimos novas pesquisas que inclusive discutam a viabilidade ética e moral de transplantes uterinos em mulheres transgênero.

\section{Referências}

BARRETO JUNIOR, Irineu Francisco; PAVANI, Miriam. O Direito à Saúde na Ordem Constitucional Brasileira. Disponível em

https://www.researchgate.net/publication/297608676 O direito a saude na ordem constitu cional_brasileira. Acesso em 18 ago. 2019.

BARRETO JUNIOR, Irineu Francisco. Atualidade do Conceito Sociedade da Informação para a Pesquisa Jurídica. In: PAESANI, Liliana Minardi (coord.). Direito na Sociedade da Informação. São Paulo: Atlas, 2007, p.62.

BARRETO JUNIOR, Irineu Francisco; VENTURI JÚNIOR, Gustavo. Dados pessoais na internet: análise do seu status enquanto mercadoria na sociedade da informação. Anais do 41'. Encontro Anual da ANPOCS. Disponível em:

http://www.anpocs.com/index.php/papers-40-encontro-2/gt-30/gt02-25/10599-dadospessoais-na-internet-analise-do-seu-status-enquanto-mercadoria-na-sociedade-dainformacao/file> Acesso em 10.nov. 2107.

BARRETO JUNIOR, Irineu Francisco. Proteção da Privacidade e de Dados Pessoais na Internet: O Marco Civil da rede examinado com fundamento nas teorias de Zygmunt Bauman e Manuel Castells. In: DE LUCCA, Newton; SIMÃO FILHO, Adalberto; DE LIMA; Cintia Rosa Pereira. (Org.). Direito \& Internet III. São Paulo: Quartier Latin, 2015. p. 100-127.

BAUMAN, Zygmunt. Amor líquido: sobre a fragilidade dos laços humanos. Rio de Janeiro: Jorge Zahar. 2004.

BRASIL. Constituição da República Federativa do Brasil. 1988.

CARDIN, Valeria Silva Galdino. Reprodução humana assistida e parentalidade responsável. Birigui: Boreal, 2016.

CASTELLS, Manuel. A Sociedade em Rede: economia, sociedade e cultura. Volume. I, a sociedade em rede. 19.ed. São Paulo: Paz e Terra, 2018.

CESAR, Vanele Rocha Falcao. Bioética e Biodireiro na sociedade pós-moderna: os direitos humanos como vetor dos experimentos científicos. Disponível em: 
http://conpedi.danilolr.info/publicacoes/0ds65m46/kz37jz13/FS49D30fw56JltfJ.pdf. Acesso em: 02 jul. 2019.

COMPARATO, Fabio Konder. A Afirmação Histórica dos Direitos Humanos. 11 ed. São Paulo: Saraiva, 2017.

CONSELHO FEDERAL DE MEDICINA. Resolução Conselho Federal de Medicina No 2168 DE 21 de setembro de 2017. Brasilia, DF. Disponível em: https://sistemas.cfm.org.br/normas/visualizar/resolucoes/BR/2017/2168. Acesso em: 01 abr.2019.

CORREIA, Maria de Jesus. Sobre a Maternidade. Disponível em:

http://www.scielo.mec.pt/pdf/aps/v16n3/v16n3a02.pdf. Acesso em 20 ago. 2019.

FERRAJOLI, Luigi. Por Uma Teoria dos Direitos e dos Bens Fundamentais. Tradução Alexandre Salim, Alfredo Copetti Neto, Daniela Cademartori, Hermes Zaneti Júnior e Sérgio Cademartori, 2011, Livraria do Advogado: Porto Alegre, p.104-105.

FULLER, Greice Patrícia; LISBOA, Roberto Senise. A saúde está “doente": uma breve reflexão introdutória da tutela jurídica à saúde e seus desdobramentos na Sociedade da Informação. In: CAVALCANTI, Ana Elizabeth; STURZA, Janaina Machado; MARTINI, Sandra Regina. A Transdisciplinaridade e o Direito. Porto Alegre: Evangraf, 2018.

GARCIA, Valter Duro. Importância do Processo Doação-Transplante. In: GARCIA, Clotilde Druck (org); PEREIRA, Japao Drose (org); GARCIA, Valter Duro (org). Doação e Transplante de Órgãos e Tecidos. São Paulo: Segmento Farma, 2015.

KOERICH, Magada Santos; MACHADO, Rosani Ramos; COSTA, Eliani. Ética e bioética: para dar início à reflexão. Disponível em: http://www.scielo.br/pdf/tce/v14n1/a14v14n1. Acesso em: 02 jul. 2019.

LEITE, Flavia Piva Almeida; SIMAO FILHO, Adalberto; VIGLIAR, José Marcelo Menezes. Inclusão da Pessoa com Deficiência na Sociedade da Informação: Considerações Sobre a Cidadania Ativa e Passiva no Processo Eleitoral Revista da Faculdade de Direito da UFG, Goias, v.40, n.2, p.152-173, jul-dez. 2016. Disponível em:

https://doi.org/10.5216/rfd.v40i2.42886. Acesso em: 02 jun.2019.

LISBOA, Roberto Senise. Direito na Sociedade da Informação. Revista dos Tribunais, São

Paulo, v. 847, maio, 2006, p.78-95.

MATOS, Lucia Helena Ouvernei Braz de; ARAUJO, Litiane Mottamarins. As desigualdades de acesso as técnicas de reprodução humana assistida. Disponível em: http://conpedi.danilolr.info/publicacoes/0ds65m46/kz37jz13/R5LeIN1q4FYkVD99.pdf. Acesso em 18 ago.2019.

MULHER, que nasceu sem útero, faz transplante e consegue gerar bebê. Globo. Rio de Janeiro:17 de dezembro, 2017. Disponível em: 
http://g1.globo.com/fantastico/noticia/2017/12/mulher-que-nasceu-sem-utero-faz-transplantee-consegue-gerar-bebe.html. Acesso em: 01, abr.2019.

NASCE primeiro bebê de mãe que recebeu transplante de útero por meio de cirurgia robótica. Revista Crescer. São Paulo: 10 de abril de 2019. Disponível em: https://revistacrescer.globo.com/Voce-precisa-saber/noticia/2019/04/nasce-primeiro-bebe-demae-que-recebeu-transplante-de-utero-por-meio-de-cirurgia-robotica.html. Acesso em: 12 abr.2019.

ORGANIZAÇÃO MUNDIAL DA SAÚDE (OMS). Constituição da Organização Mundial da Saúde. Disponível em espanhol em:

http://www.who.int/governance/eb/who_constitution_sp.pdf. Acesso: 02 ago. 2019.

ORGANIZAÇÃO PANAMERICANA DE SAÚDE (OPAS). Indicadores de saúde: elementos conceituais e práticos. Disponível em:

https://www.paho.org/hq/index.php?option=com_content\&view=article\&id=14401:healthindicators-conceptual-and-operational-considerations-section1\&Itemid=0\&showall=1\&lang=pt . Acesso em: 02 de ago. 2019.

PENNA, Moira Maxwell; DUARTE, Ivolethe; COHEN, Claudia; OLIVEIRA, Reinaldo Ayer de. Concepções sobre o principio da não maleficência e suas relações com prudência. Disponível em: http://revistabioetica.cfm.org.br/index.php/revista bioetica/article/view/717/739. Acesso em: 02 jul. 2019.

ROCHA, Carmen Lucia Antunes. Voto. Disponível em: http://www.stf.jus.br/arquivo/cms/noticiaNoticiaStf/anexo/adi3510CL.pdf. Acesso em 02 jul. 2019.

SANCHES, Samyra Haydêe Dal Farra Naspolini; CAVALCANTI, Ana Elizabeth Lapa Wanderley. Direito à saúde na Sociedade da Informação: a questão Das fake news e seus impactos na vacinação. Disponível em:

http://revista.unicuritiba.edu.br/index.php/RevJur/article/view/3227/371371743. Acesso em: 02 jul 2019.

SAKAR, Dibyangshu. Primeiro transplante de útero na França levanta questão ética. Rfi Brasil, França: 12 abril de 2019. Disponível em: http://br.rfi.fr/franca/20190412-primeirotransplante-de-utero-na-franca-levanta-questao-etica. Acesso em: 12 abr.2019.

SINDHOSP: Saúde um Desafio Mundial. Anuário 2010.p.59.

SOUZA, Paulo Vinicius Sporleder de. Bem jurídico penal e engenharia genética humana: contribucto para a compreensão dos bens jurídicos supra-individuais. São Paulo: Revista dos Tribunais, 2004.

STANCIOLI, Brunelo; CARVALHO, Nara Pereira; RIBEIRO, Daniel Mendes; LARA, Mariana Alves. O Sistema Nacional de Transplantes: Saúde e Autonomia em Discussão. Revista de Direito Sanitário. São Paulo, v. 11, n. 3 p. 123-154 Nov. 2010/Fev. 2011. 
Disponível em: https://www.revistas.usp.br/rdisan/article/view/13225/15040. Acesso em: 01 abr.2019.

SIPPERT, Evandro Luis; SRURZA, Janaina. Da prestação sanitária à efetivação do direito à saúde: breves delineamentos internacionais. In: CAVALCANTI, Ana Elizabeth; STURZA, Janaina Machado; MARTINI, Sandra Regina. A Transdisciplinaridade e o Direito. Porto Alegre: Evangraf, 2018.

TRANSPLANTE uterino. FEBRASGO São Paulo, 21 junho, 2017. Disponível em https://www.febrasgo.org.br/pt/noticias/item/115-transplante-uterino. Acesso em 01 abr.2019.

VENTURA, Miriam. Direitos reprodutivos no Brasil. 3 ed. Brasília/DF: UNFPA, 2009.

WALDMAN, Ricardo Libel. Obejtivo do desenvolvimento sustentável n.3: a saúde 2.0 e a aplicação do principio da precaução na Sociedade da Informação. In: CAVALCANTI, Ana Elizabeth; STURZA, Janaina Machado; MARTINI, Sandra Regina. A Transdisciplinaridade e o Direito. Porto Alegre: Evangraf, 2018.

ZALAZAR, Claudia Elizabeth; CARRANZA, Gonzalo Gabriel. Aproximación sistémica al concepto de derecho a la salud. In: CAVALCANTI, Ana Elizabeth; STURZA, Janaina Machado; MARTINI, Sandra Regina. A Transdisciplinaridade e o Direito. Porto Alegre: Evangraf, 2018. 